\title{
Molecular docking-based screening for novel inhibitors of the human immunodeficiency virus type 1 protease that effectively reduce the viral replication in human cells
}

\section{Carla Mavian ${ }^{1 a}$, Roxana M Coman ${ }^{1,2 a}$, Xinrui Zhang ${ }^{1}$, Steve Pomeroy ${ }^{1}$, David A. Ostrov ${ }^{1}$, Ben M Dunn², John W. Sleasman ${ }^{3}$ and Maureen M Goodenow ${ }^{4 *}$}

1 Department of Pathology, Immunology and Laboratory Medicine, College of Medicine, University of Florida, Gainesville, Florida, USA

2 Department of Biochemistry and Molecular Biology, College of Medicine, University of Florida, Gainesville, Florida, USA

3 Pediatric Allergy, Immunology, and Pulmonary Medicine, Duke University, Durham, NC 27710

4 Office of AIDS Research, National Institutes of Health

$\mathrm{a}=\mathrm{CM}$ and RMC contributed equally to this article

${ }^{*}=$ Corresponding author. E-mail: maureen.goodenow@nih.gov

\begin{abstract}
Therapeutic pressure by protease inhibitors (PIs) contributes to accumulation of mutations in the HIV type 1 (HIV-1) protease (PR) leading to development of drug resistance with subsequent therapy failure. Current Pls target the active site of PR in a competitive manner. Identification of molecules that exploit non-active site mechanisms of inhibition is essential to overcome resistance to current PIs. Potential non-active site HIV-1 protease (PR) inhibitors (PI) were identified by in silico screening of almost 140,000 molecules targeting the hinge region of PR. Inhibitory activity of best docking compounds was tested in an in vitro PR inhibition biochemical assay. Five compounds inhibited PR from multiple HIV-1 subtypes in vitro and reduced replicative capacity by PI-sensitive or multi-PI resistant HIV-1 variants in human cells ex vivo. Antiviral activity was boosted when combined with Ritonavir, potentially diminishing development of drug resistance, while providing effective treatment for drug resistant HIV-1 variants.
\end{abstract}

Keywords: HIV-1; molecular docking; non-active site targeting; protease inhibitors

\section{Introduction}

With no available cure, treatment of HIV infection requires life-long therapy. The landscape of HIV treatment has significantly benefited from the approval of multidrug combinations of antiretroviral therapies (CART) based on several new antiretroviral drugs (ARVs) with enhanced potency, safety and tolerability. Since introduction of ARVs for pre-exposure prophylaxis (PrEP) in 2012 as a measure of HIV prevention, HIV transmission has substantially decreased $(1,2)$. However, every year approximately 2 million new HIV infections are reported worldwide, of which 50,000 are in the U.S. (3). Effective strategies to prevent HIV transmission are needed as successful implementation and worldwide breadth of PrEP represent still a challenge. HIV research attention remains focused on the developing long-acting ARVs to mitigate drug adherence and resistance issues.

Among the pharmacologic agents undergoing evaluation for use as PrEP, earlier phase studies are currently evaluating protease inhibitors (PIs) for intravaginal rings (4). Inhibiting PR prevents maturation of viral progeny, compromises further entry and inhibits viral spread $(5,6)$. Including Pls in CART has significantly improved length and quality of life of HIV infected individuals $(5,7)$. However, currently Pls in use present side effects of antiretroviral drugs, development of drug resistance, and transmission of multidrug resistant strains in $9 \%$ to $15 \%$ of new infections represent major challenges for successful cART (8-10). HIV type 1 (HIV-1) PR is a homodimeric enzyme of 99 amino acids [aa] essential for HIV replication (6). Although, inhibition of HIV-1 PR enzymatic activity by competitive inhibition of substrate binding in the active site has pleiotropic effects on the viral life cycle (6), one of the major drawbacks is the emergence of viral species exhibiting resistance to Pls that limits long-term treatment options. Design of Pls efficient against multi-drug resistant PR is fundamental to overcome development of resistance. Novel mechanisms of inhibiting PR target the flexibility of the enzyme in non-active sites, such as the elbow/hinge region of the flaps (aa 39-42), the tip of the flap (aa 43-58), or the $\beta$-sheet region (aa 1-5, 95-99) (11-13). The flaps close to initiate processing once substrate binds in the active site of PR. Inhibition of the flaps would theoretically 
change the conformation of PR and modulate the active site (14). The nature of the interaction of non-active site PIs with the PR may also decrease the therapeutic index of current Pls by reducing dosage or frequency of administration, and potentially minimizing side effects. Previously, nonactive site PIs have been identified and tested against HIV-1 PR in biochemical assays, although evidence for effectiveness reduction of HIV-1 infection in human cells is lacking $(11,13,15)$. We explored the hypothesis that compounds selected by in silico binding to the hinge region of PR are effective as inhibitors of viral replication, including multi-PI resistant viruses, in human cells.

\section{Materials and methods}

Molecular Docking. The whole repository of 139,739 small molecules (molecular weight, $<500$ ) of the National Cancer Institute/Developmental Therapeutics Program (NCl/DTP) was screened for identification of novel Pls (16). The three-dimensional coordinates of the 139,739 $\mathrm{NCI} / \mathrm{DTP}$ compounds were obtained in MDL SDF-format and converted to mol2 format with SDF2MOL2 (UCSF). Molecular docking was performed with DOCK v5.1.0 (i) selecting for structural pockets in HIV-1 PR suitable for interactions with drug-like small molecules and (ii) performing molecular docking simulations where each small molecules is positioned in the selected structural pocket and scored based on predicted polar (H-bond) and nonpolar (van der Waals) interactions (17). Docking calculations were performed with the 15 October 2002 development version of DOCK v5.1.0 (18).

The crystal structure of HIV protease (PDB code 1TW7) was used the basis for molecular docking (19). Molecular docking was realized on conserved residues located on the side of the PR grove formed by the elbow of the flap and the 60's loop (43-58 aa) (Fig S1). DOCK explores the molecular surface using sets of spheres as a guide to search for orientations of each molecule that fit into the selected sites to describe potential binding pockets. The sites selected for molecular docking were defined using the SPHGEN program and filtered through the CLUSTER program (20). Seventy-two spheres were used to define the HIV-1 PR site for molecular docking. Each compound in the NCl/DTP database was positioned in the selected site in 100 different orientations at the University of Florida High Performance Computing Center. Intermolecular AMBER energy scoring (van der Waals_columbic), contact scoring, and bump filtering were implemented in DOCK v5.1.0. PYMOL (https://www.pymol.org/) was used to generate molecular graphic images (21).

In vitro PR inhibition assays. The compounds were obtained from the NCI/DTP and solubilized in DMSO (Sigma) for use in HIV-1 PR inhibition assays. Cloning, expression, and purification procedures of HIV-1 PRs obtained from patent samples has been previously described elsewhere (22-24). For detailed information of mutations harbored in the multi PI-resistant HIV-1PR as compared to the PI-sensitive PR, full amino acid sequences is given in supplementary materials (Fig S2). HIV-1 PRs subtype variants were assayed kinetically for inhibitory activity at $80 \mu \mathrm{M}$ at 37 ${ }^{\circ} \mathrm{C}$ using selected compounds as previously described (22).

Cell culture. TZM-bl cells (ARP5011) with an integrated luciferase gene under the control of the HIV-1 promoter were obtained through the NIH AIDS Research and Reference Reagent Program, Division of AIDS $(25,26)$. TZM-bl cells were cultured in DMEM media (Gibco) containing $10 \%$ fetal human serum (FHS), $2 \mathrm{mM}$ L-Glutamine, $0.05 \%$ sodium bicarbonate and $0.1 \mathrm{mg} / \mathrm{ml}$ Penicillin and Streptomycin. Peripheral blood mononucleated cell (PBMCs) were obtained from Lifesouth Community Blood Center, Gainesville, FL. with approval for use of human cells by the Institutional Review Board. PBMCs were stimulated with phytohemaglutinin $(2 \mathrm{mg} / \mathrm{ml})$ for 72 hours and cultured in RPMI Medium (Gibco) with 10\% FHS. Both cell types were kept in an incubator at $37^{\circ} \mathrm{C}$ with $5 \% \mathrm{CO}_{2}$.

HIV-1 PI-sensitive and multi PI-resistant variants. Virus stocks of the CCR5 using, replication competent PI-sensitive (HIV-1 $\mathrm{AD}$ ) or multi (Ritonavir (RTV) and Indinavir) PI-resistant (HIV-1 AD02 $_{2}$ HIV-1 variants were prepared by transfecting plasmid DNA from a molecular clone into 293T cells and titered as described previously (27). Briefly, the molecular clone pAD8 (Theodore et al, 1996), a stable full-length macrophage-tropic HIV type 1 molecular clone, was used to generate a protease inhibitor-resistant molecular clone: a viral isolate from a PR drug-resistant patient was used to generate amplified DNA gag-pol amplicons as previously described by our laboratory (28, 
29). The drug-resistant $P R$ was obtained from the replication competent virus present in the peripheral blood of a patient who had failed PIs $(28,29)$. The gag-pol regions carried by the PIsensitive (HIV-1 $\left.1_{A D}\right)$ and the multi PI-resistant (HIV-1 $\left.1_{A D 02}\right)$ HIV-1 variants have been well characterized by our laboratory (28) (Fig S2).

Cell viability assays. Viability in presence of compounds was measured at day 4 or 7 , TZM-bl cells or PBMCs, using CellTiter 96 AQueous one solution cell proliferation assay (Promega) following manufacturer instructions. Toxicity of compounds was defined as a concentration that produced more than $10 \%$ decline in viability of TZM-bl cells or PBMCs were viable at days 4 or 7 of exposure, respectively, compared with DMSO-treated controls $(28,30,31)$.

HIV- infection and anti-viral activity assays. Anti-viral activity was evaluated ex vivo by adding the highest non-toxic concentration of compound or 25 uM RTV (Sigma) solubilized in DMSO on the day of infection by PI-sensitive (HIV-1 $\mathrm{AD}$ ) or multi (RTV and IDV) PI-resistant (HIV$\left.1_{\mathrm{AD} 02}\right) \mathrm{HIV}-1$ variants at 25 or $45 \mathrm{TCID}_{50}$ per $\mathrm{ml}$ for PBMCs or TZM-bl cells, respectively. Replication was determined on post-infection day 7 in PBMC by measuring supernatant p24 antigen levels (Perkin-Elmer), or day 4 in TZM-bl cells by measuring luciferase activity using the luciferase assay system (Promega, Madison, WI) and the microplate luminometer Monolight 3096 (BD Biosciences, San Jose, CA). Inhibitory concentration (IC) 50 was calculated based on anti-viral activity in TZM-bI cells with a nonlinear regression analysis (GraphPad Prism 6 Software). Reduction of viral replication by more than $50 \%$ was considered successful anti-viral activity. Combinatorial effect of drug with RTV was tested at IC $\mathrm{C}_{50}$, and higher or lower concentrations than $\mathrm{IC}_{50}$.

Statistical analysis. Linear mixed models with Bonferroni correction to adjust for multiple comparisons were performed with SAS/STAT 9.4 Software.

\section{Results}

\section{Identification of compounds that inhibit the $P R$ through targeting $P R$ non-active sites}

We explored the hypothesis that compounds selected in silico for binding to the hinge region of $\mathrm{PR}$ are effective as inhibitors of HIV-1 replication, including multi-PI resistant viruses, in human cells. Our of 139,739 compounds, the top 40 highest-scoring compounds targeting the structural pockets in the hinge of the PR (Fig S2) were obtained from the NCI/DTP for use in HIV PR inhibition assays. Compounds were initially tested in vitro at $80 \mu \mathrm{M}$ to screen for inhibitory activity against PR subtypes A, B or C. Compounds inhibiting at least one subtype of the PR were considered as candidate compounds for further experiments. Out of the 40 top scoring compounds, 12 compounds inhibited subtype B PR; 11 also inhibited subtype C PR, while 8 inhibited subtype A PR. Compounds that have been identified as Pls candidates are reported in Table 1.

Afterwards, we tested the 12 compounds for toxicity in human cells. A compound was considered toxic when that produced more than $10 \%$ decline in viability of TZM-bl cells or PBMCs at a certain concentration (Table S1). In TZM-bl cells, compound 19 was toxic at $200 \mu \mathrm{M}$ reducing cell viability of $28 \%$ at $200 \mu \mathrm{M}$, compounds 32 and 35 were toxic at concentrations higher than $25 \mu \mathrm{M}$ reducing cell viability of more than $50 \%$, while nine compounds [compounds $1,8,18,22,27,24,36$, 37 and 39] were non-toxic at $200 \mu \mathrm{M}$. Compounds showed greater toxic effect in PBMCs: while only four compounds [compounds $8,34,36,37$ and 39] were non-toxic at $200 \mu \mathrm{M}$; compounds 18 or 22 were toxic at $200 \mu \mathrm{M}$ reducing cell viability of $28 \%$ or $20 \%$, respectively; compounds 19,32 or 35 were toxic at $50 \mu \mathrm{M}$, reducing cell viability of $24 \%, 32 \%$ or $29 \%$, respectively; while compound 27 reduced cell viability of $50 \%$ at $25 \mu \mathrm{M}$. Compound 1 did not show toxicity in TZM-bl cells, however reduced viability of PBMC by $28 \%$ at $10 \mu \mathrm{M}$ and by $30 \%$ at higher concentrations, and therefore was not considered in further testing.

Table 1. Chemical characteristics and inhibitory activity of selected compounds.

\begin{tabular}{cccccccc}
\hline & \multicolumn{4}{c}{ Characteristics of compounds } & \multicolumn{3}{c}{ Inhibition of PR subtype } \\
\hline $\mathbf{N C l}$ & ID & DS & MW & MF & A & B & C \\
\hline $\mathbf{1 5 9 4 5 6}$ & 1 & -36.8 & 338.3 & $\mathrm{C}_{19} \mathrm{H}_{14} \mathrm{O}_{6}$ & + & + & + \\
$\mathbf{6 3 6 9 8 3}$ & 8 & -33.0 & 396.3 & $\mathrm{C}_{19} \mathrm{H}_{12} \mathrm{~N}_{2} \mathrm{O}_{8}$ & + & + & + \\
\hline
\end{tabular}




\begin{tabular}{cccccccc}
\hline $\mathbf{1 1 7 2 8 5}$ & 18 & -31.7 & 289.3 & $\mathrm{C}_{11} \mathrm{H}_{11} \mathrm{~N}_{7} \mathrm{O}_{3}$ & + & + & + \\
$\mathbf{6 0 0 4 4}$ & 19 & -31.6 & 336.2 & $\mathrm{C}_{15} \mathrm{H}_{11} \mathrm{Cl}_{2} \mathrm{~N}_{3} \mathrm{O}_{2}$ & + & + & + \\
$\mathbf{6 4 9 1 5 2}$ & 22 & -31.6 & 273.3 & $\mathrm{C}_{13} \mathrm{H}_{11} \mathrm{~N}_{3} \mathrm{O}_{2} \mathrm{~S}$ & - & + & + \\
$\mathbf{2 9 5 2 7 4}$ & 27 & -31.2 & 387.4 & $\mathrm{C}_{17} \mathrm{H}_{17} \mathrm{~N}_{5} \mathrm{O}_{6}$ & + & + & + \\
$\mathbf{1 0 3 6 5 0}$ & 32 & -31.0 & 435.3 & $\mathrm{C}_{22} \mathrm{H}_{16} \mathrm{Cl}_{2} \mathrm{~N}_{6}$ & + & + & + \\
$\mathbf{1 1 8 2 1 0}$ & 34 & -30.9 & 303.3 & $\mathrm{C}_{12} \mathrm{H}_{9} \mathrm{~N}_{5} \mathrm{O}_{3} \mathrm{~S}$ & - & + & - \\
$\mathbf{6 6 3 6 1 9}$ & 35 & -30.7 & 310.3 & $\mathrm{C}_{18} \mathrm{H}_{10} \mathrm{~N}_{6}$ & + & + & + \\
$\mathbf{8 4 1 2 0}$ & 36 & -30.6 & 290.2 & $\mathrm{C}_{11} \mathrm{H}_{10} \mathrm{~N}_{6} \mathrm{O}_{4}$ & - & + & + \\
$\mathbf{1 0 7 1 9 2}$ & 37 & -30.6 & 328.3 & $\mathrm{C}_{15} \mathrm{H}_{16} \mathrm{~N}_{6} \mathrm{O}_{3}$ & - & + & + \\
$\mathbf{1 2 9 9 4}$ & 39 & -30.6 & 310.3 & $\mathrm{C}_{13} \mathrm{H}_{14} \mathrm{~N}_{2} \mathrm{O}_{7}$ & + & + & + \\
\hline
\end{tabular}

$\mathrm{NCl}$ : database number; ID: compound identification number; DS: docking score expressed in kcal $\mathrm{mol}^{-1}$; MW: molecular weight; MF: molecular formula. [+] or [-] indicating PR inhibition or no inhibition, respectively.

\section{Anti-viral activity of five lead compounds as novel Pls}

Screening for anti-viral activity was evaluated ex vivo by adding the compound at the highest non-toxic concentration on the day of infection with either PI-sensitive or multi-PI-resistant HIV-1 variants (Fig 1). In PBMC, compounds 27 and 36 reduced replication of PI-sensitive HIV-1 ${ }_{A D}$ by more than $60 \%$, while compounds 18 , 22, or 35 reduced replication $80 \%$ to $90 \%$ (Fig 1 A). Replication of multi-drug resistant HIV-1AD02 was reduced by several compounds to levels that were greater than PR sensitive virus, but similar to levels of inhibition by RTV, classic active site PI (Fig 1A). Although compounds were less effective against PR resistant virus in TZM-bl cells, compounds 18, 27 or 32 reduced replication by both viruses more than $80 \%$ (Fig 1B). Some compounds showed discordant performance in PBMCs and TZM-bl cells, and therefore in our further investigation, we analyzed compounds that presented the same trend in both cells: five compounds $(18,22,27,32$ and 35$)$ inhibited HIV-1 variants in human primary lymphocytes and TZM-bl cells. The $\mathrm{IC}_{50}$ of 18 or 27 for either HIV-1 variant was almost identical, being $62.7 \mu \mathrm{M}$ and $68.5 \mu \mathrm{M}$ [compound 18] and $26.0 \mu \mathrm{M}$ and $27.1 \mu \mathrm{M}$ [compound 27], for HIV-1 AD or HIV-1 AD02 respectively. IC 50 of compounds 22, 32 and 35 were $53.5 \mu \mathrm{M}$ or $71.9 \mu \mathrm{M}, 3.8 \mu \mathrm{M}$ or $13.7 \mu \mathrm{M}$, and $1.4 \mu \mathrm{M}$ or $6.3 \mu \mathrm{M}$ for HIV-1 $1_{A D}$ or HIV-1 ${ }_{A D 02}$, respectively; that is 1.3-fold, 3.6-fold or 4.5-fold lower for HIV-1 $1_{A D}$ as compared to HIV-1 $1_{A D 02}$, respectively. As previous allosteric PIs (11-13), the five lead compounds that we report presented aromatic structures (Fig S3).

Combinatorial effect of drug was tested combining $25 \mu \mathrm{M}$ RTV and higher or lower concentrations than $\mathrm{IC}_{50}$ of lead compounds. Combinations of compounds 18, 22, 27, 32 or 35 with $25 \mu \mathrm{M}$ RTV were non-toxic in TZM-bl cells. Combination with RTV increased antiviral activity of all compounds against both PI-sensitive and PI-resistant HIV-1 variants (Fig 2). Combinations of RTV with lead compounds were more effective than $25 \mu \mathrm{M}$ RTV alone against either HIV-1 $\mathrm{AD}$ or HIV1AD02: RTV with compound 32 at $10 \mu \mathrm{M}$, compound 35 at $25 \mu \mathrm{M}$, or compounds 22 or 27 at 50 and $100 \mu \mathrm{M}$ respectively, were more effective than $25 \mu \mathrm{M}$ RTV alone (Fig 2; Table S2). While no compound alone inhibited HIV-1 variants to the extent of inhibition by $25 \mu \mathrm{M}$ RTV, combinations of RTV with compound 18 at 50 and $100 \mu \mathrm{M}$ were more effective than $25 \mu \mathrm{M}$ RTV alone against HIV-

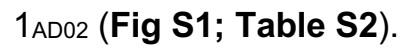

A

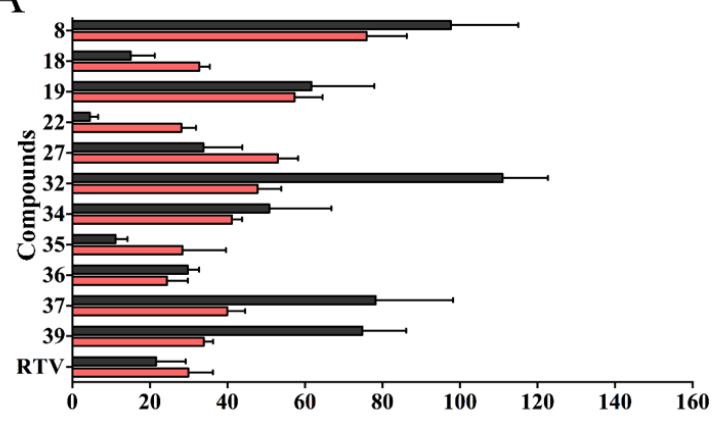

B

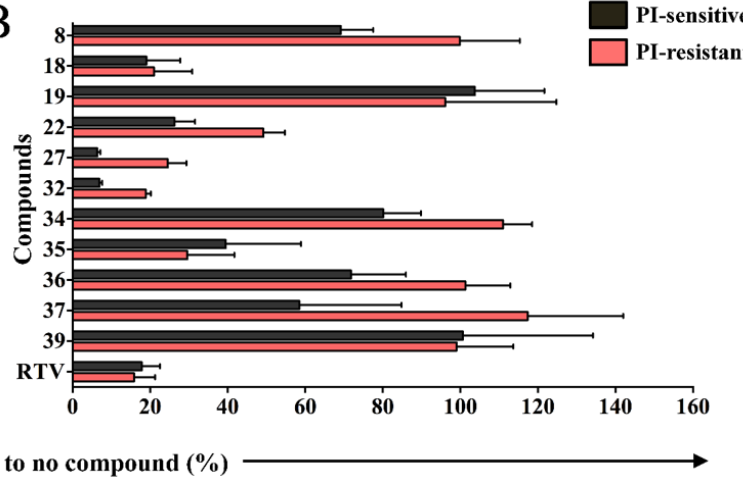


Figure 1. Anti-viral activity screening of compounds in human cells. (A) PBMCs or (B) TZM-bl cells infected with HIV-1 $1_{A D}$ (black) or HIV-1 $1_{A D 02}$ (red) in presence of compounds. Data are expressed as mean and standard deviation.

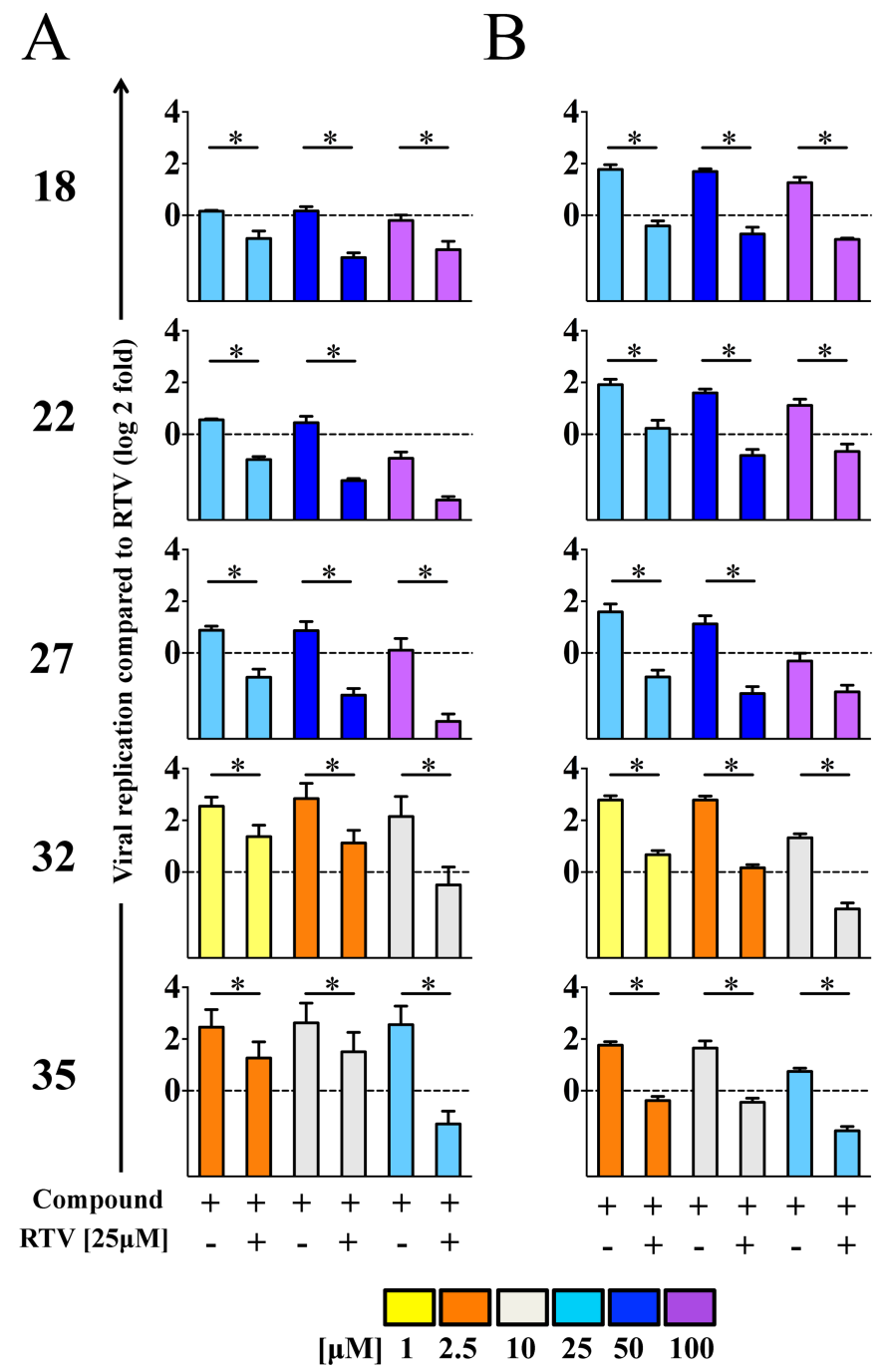

Fig 2. Anti-viral activity of lead compounds in combination with RTV. Anti-viral activity against HIV-1 $1_{\mathrm{AD}}(\mathrm{A})$ or HIV-1 $1_{\mathrm{AD} 02}(\mathrm{~B})$ of compounds alone or in combination with 25 $\mu \mathrm{M}$ RTV expressed as fold-change relative to RTV (dotted line). Data are expressed as mean and standard deviation. Linear mixed models with Bonferroni correction were performed to adjust for multiple comparisons (SAS/STAT 9.4). Asterisks show statistically significant differences $(p<0.05 / 9=0.0055)$.

\section{Discussion}

Long-term success of HIV therapy requires both efficacy and safety/tolerability and novel drug development for patients with drug resistance. HIV-1 resistance to anti-retroviral drugs develops with suboptimal levels of inhibitor and is associated with high risk of therapy failure (6). Discovery of drugs that exploit alternative mechanisms of HIV inhibition is essential to avoid or prevent further development of drug-resistance. Our study presents a set of molecules that have similar antiviral activity against PI-resistant and PI-sensitive HIV-1 variants, both in vitro and ex vivo assays, consistent with a non-active site targeting mechanism. These non-active site Pls were able to inhibit HIV-1 infection by molecular clones generated ex vivo from PI-sensitive and PI-resistant naturally occurring HIV-1 variants. 
This is the first report of novel Pls that are effectively reducing HIV-1 infection in human cells. PIs that target sites other than the active site in PR would overcome current drug-resistant variants by not competing with natural substrates, and their effect would be undiminished by higher concentrations of substrate $(12,15)$. Our study design based on in silico modeling to find novel Pls that target the non-active site of HIV-1 PR, is supported by in vitro studies with similar compounds defined as allosteric Pls (32). Recently, a hinge PI was reported to act by a non-competitive mechanism when delivered together with an active site drugs (13). However, our study presents two caveats. The compounds we describe are a first generation compound that requires further optimization. Further structure-activity modulation of these compounds would lead to the development of more effective molecules with an anti-viral activity at concentrations that would be suitable for pharmaceutical use. Second, preliminary attempts to obtain a crystal structure of the HIV-1 protease bound to the compounds failed. This suggests that the binding of the compounds destabilizes the enzyme inducing a conformation, which differs from the classical PI binding, as reported as well by Tiefenbrunn et al, which would be in agreement with our simulation (11). Despite the PR-compounds crystals are not available, our results are consistent with non-active site mechanism of inhibition. The similar anti-viral activity against PI-sensitive and PR-resistant HIV-1 variants suggests that the PR of the PI-resistant variant is naïve to the inhibitory mechanism exploited by the compounds. Indeed, the RTV boosting effect we observed when combining RTV with the lead compounds, is also consistent with, but not proof of, a non-active site inhibition mechanism. The cooperative action of non-active site and catalytic site inhibitors increases the effectiveness of inhibition of an enzyme, and is a successful approach used with nucleoside and non-nucleoside inhibitors of HIV-1 reverse transcriptase (NRTI and NNRTI, respectively) in CART (33), as well as in cancer chemotherapy (34). Under the selective pressure of multiple Pls acting with different inhibitory mechanism, drug-naïve PRs would have more limitation to escape both classes of inhibitors. Although monotherapy regimes based on NNRTIs leads to resistance, the combination with NRTIs suppresses the evolution of RT resistance $(11,33)$. A similar scenario may be possible for $\mathrm{PI}$-based therapy regimes if allosteric inhibitors would be delivered. There was no significant toxicity observed in PBMCs suggesting that with further chemical modification, these molecules may be delivered at pharmacological concentrations and tolerated by human cells. Overall, these non-active site PIs with multi-cell effectiveness represent promising approaches to expand the repertoire of current PIs to attenuate viral replication and prevent therapy resistance current Pls repertoire. Our study evaluated the impact of inhibitors in acute infection of primary lymphocytes, as the compounds were included on the day of infection. Future experiments are needed to test effect of non-active site PIs on longer term chronic infection in primary lymphocytes or latent cells.

Acknowledgments: We want to thank Dr. Julie C. Williams for her help revising the manuscript. All authors declare no conflict of interest.

Funding section: This study was supported in part by NIH R01 Al28571 (B.M.D., M.M.G. and S.P.); Stephany W. Holloway University Chair for HIVIAIDS Research (M.M.G.); and Laura McClamma Fellowship (C.M., R.M.C. and X.Z.).

\section{References}

1. Prejean J, Song R, Hernandez A, Ziebell R, Green T, Walker F, et al. Estimated HIV incidence in the United States, 2006-2009. PLoS One. 2011;6(8):e17502.

2. Joint United Nations Programme on HIVIAIDS (UNAIDS). UNAIDS Report on the Global AIDS Epidemic. 2013.

3. WHO. HIVIAIDS, Fact sheet N³60, Updated November 2015. http://wwwwhoint/mediacentre/factsheets/fs360/en/. 2015

4. Vaginal Rings: Products in development for HIV prevention and multipurpose technologies. AIDS Vaccine Advocacy Coalition. 2014.

5. Konvalinka J, Krausslich HG, Muller B. Retroviral proteases and their roles in virion maturation. Virology. 2015;479-480C:403-17. 
6. Adamson CS. Protease-Mediated Maturation of HIV: Inhibitors of Protease and the Maturation Process. Mol Biol Int. 2012;2012:604261.

7. Volberding PA, Deeks SG. Antiretroviral therapy and management of HIV infection. Lancet. 2010;376(9734):49-62.

8. Johnson VA, Calvez V, Gunthard HF, Paredes R, Pillay D, Shafer RW, et al. Update of the drug resistance mutations in HIV-1: March 2013. Top Antivir Med. 2013;21(1):6-14.

9. Menendez-Arias L. Molecular basis of human immunodeficiency virus drug resistance: an update. Antiviral Res. 2010;85(1):210-31.

10. Vercauteren J, Wensing AM, van de Vijver DA, Albert J, Balotta C, Hamouda O, et al. Transmission of drug-resistant HIV-1 is stabilizing in Europe. The Journal of infectious diseases. 2009;200(10):1503-8.

11. Tiefenbrunn T, Forli S, Baksh MM, Chang MW, Happer M, Lin YC, et al. Small molecule regulation of protein conformation by binding in the Flap of HIV protease. ACS Chem Biol. 2013;8(6):1223-31.

12. Damm KL, Ung PM, Quintero JJ, Gestwicki JE, Carlson HA. A poke in the eye: inhibiting HIV1 protease through its flap-recognition pocket. Biopolymers. 2008;89(8):643-52.

13. Kunze J, Todoroff N, Schneider P, Rodrigues T, Geppert T, Reisen F, et al. Targeting dynamic pockets of HIV-1 protease by structure-based computational screening for allosteric inhibitors. J Chem Inf Model. 2014;54(3):987-91.

14. Scott WR, Schiffer CA. Curling of flap tips in HIV-1 protease as a mechanism for substrate entry and tolerance of drug resistance. Structure. 2000;8(12):1259-65.

15. Hornak V, Simmerling C. Targeting structural flexibility in HIV-1 protease inhibitor binding. Drug Discov Today. 2007;12(3-4):132-8.

16. Monga M, Sausville EA. Developmental therapeutics program at the NCl: molecular target and drug discovery process. Leukemia. 2002;16(4):520-6.

17. Moustakas DT, Lang PT, Pegg S, Pettersen E, Kuntz ID, Brooijmans N, et al. Development and validation of a modular, extensible docking program: DOCK 5. J Comput Aided Mol Des. 2006;20(10-11):601-19.

18. Perola E, Walters WP, Charifson PS. A detailed comparison of current docking and scoring methods on systems of pharmaceutical relevance. Proteins. 2004;56(2):235-49.

19. Martin P, Vickrey JF, Proteasa G, Jimenez YL, Wawrzak Z, Winters MA, et al. "Wide-open" 1.3 A structure of a multidrug-resistant HIV-1 protease as a drug target. Structure. 2005;13(12):1887-95.

20. Ewing TJ, Makino S, Skillman AG, Kuntz ID. DOCK 4.0: search strategies for automated molecular docking of flexible molecule databases. J Comput Aided Mol Des. 2001;15(5):41128.

21. DeLano WL. The case for open-source software in drug discovery. Drug Discov Today. 2005;10(3):213-7.

22. Coman RM, Robbins AH, Fernandez MA, Gilliland CT, Sochet AA, Goodenow MM, et al. The contribution of naturally occurring polymorphisms in altering the biochemical and structural characteristics of HIV-1 subtype C protease. Biochemistry. 2008;47(2):731-43.

23. Clemente JC, Coman RM, Thiaville MM, Janka LK, Jeung JA, Nukoolkarn S, et al. Analysis of HIV-1 CRF_01 A/E protease inhibitor resistance: structural determinants for maintaining sensitivity and developing resistance to atazanavir. Biochemistry. 2006;45(17):5468-77.

24. Goodenow MM, Bloom G, Rose SL, Pomeroy SM, O'Brien PO, Perez EE, et al. Naturally occurring amino acid polymorphisms in human immunodeficiency virus type 1 (HIV-1) Gag $\mathrm{p} 7(\mathrm{NC})$ and the C-cleavage site impact Gag-Pol processing by HIV-1 protease. Virology. 2002;292(1):137-49.

25. Wei X, Decker JM, Liu H, Zhang Z, Arani RB, Kilby JM, et al. Emergence of resistant human immunodeficiency virus type 1 in patients receiving fusion inhibitor (T-20) monotherapy. Antimicrob Agents Chemother. 2002;46(6):1896-905.

26. Derdeyn CA, Decker JM, Sfakianos JN, Wu X, O'Brien WA, Ratner L, et al. Sensitivity of human immunodeficiency virus type 1 to the fusion inhibitor T-20 is modulated by coreceptor specificity defined by the V3 loop of gp120. J Virol. 2000;74(18):8358-67.

27. Theodore TS, Englund G, Buckler-White A, Buckler CE, Martin MA, Peden KW. Construction and characterization of a stable full-length macrophage-tropic HIV type 1 molecular clone that directs the production of high titers of progeny virions. AIDS Res Hum Retroviruses. 1996;12(3):191-4.

28. Ho SK, Coman RM, Bunger JC, Rose SL, O'Brien P, Munoz I, et al. Drug-associated changes in amino acid residues in Gag p2, p7(NC), and p6(Gag)/p6(Pol) in human 
immunodeficiency virus type 1 (HIV-1) display a dominant effect on replicative fitness and drug response. Virology. 2008;378(2):272-81.

29. Peden K, Emerman M, Montagnier L. Changes in growth properties on passage in tissue culture of viruses derived from infectious molecular clones of HIV-1LAI, HIV-1MAL, and HIV1ELI. Virology. 1991;185(2):661-72.

30. Naarding MA, Fernandez N, Kappes JC, Hayes P, Ahmed T, Icyuz M, et al. Development of a luciferase based viral inhibition assay to evaluate vaccine induced CD8 T-cell responses. J Immunol Methods. 2014;409:161-73.

31. Williams JC, Appelberg S, Goldberger BA, Klein TW, Sleasman JW, Goodenow MM. Delta(9)-Tetrahydrocannabinol treatment during human monocyte differentiation reduces macrophage susceptibility to HIV-1 infection. J Neuroimmune Pharmacol. 2014;9(3):369-79.

32. Ung PM, Dunbar JB, Jr., Gestwicki JE, Carlson HA. An allosteric modulator of HIV-1 protease shows equipotent inhibition of wild-type and drug-resistant proteases. J Med Chem. 2014;57(15):6468-78.

33. De Clercq E. Perspectives of non-nucleoside reverse transcriptase inhibitors (NNRTIs) in the therapy of HIV-1 infection. Farmaco. 1999;54(1-2):26-45.

34. Zhang J, Adrian FJ, Jahnke W, Cowan-Jacob SW, Li AG, lacob RE, et al. Targeting Bcr-Abl by combining allosteric with ATP-binding-site inhibitors. Nature. 2010;463(7280):501-6.

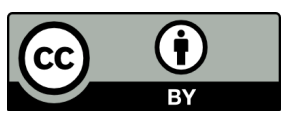

(C) 2019 by the authors. Submitted for possible open access publication under the terms and conditions of the Creative Commons Attribution (CC BY) license (http://creativecommons.org/licenses/by/4.0/).

\section{Mavian et al. Supplementary Information}

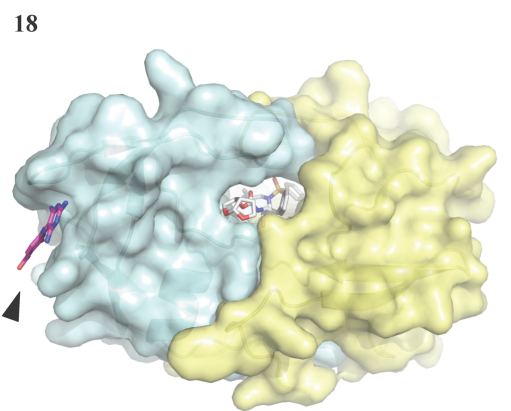

32

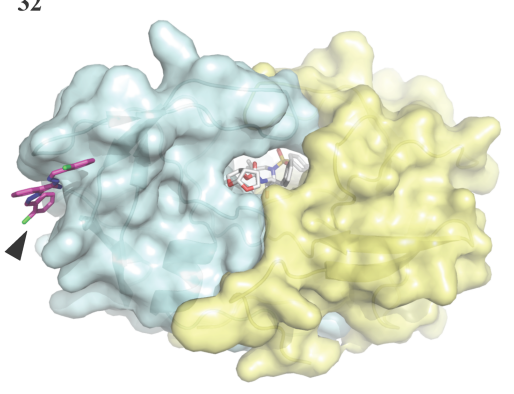

22

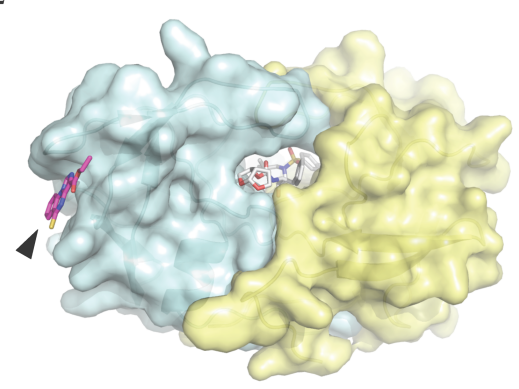

35

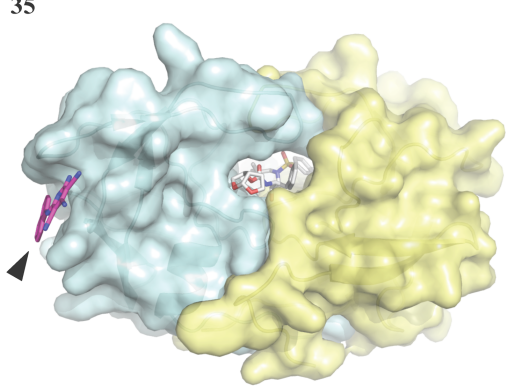

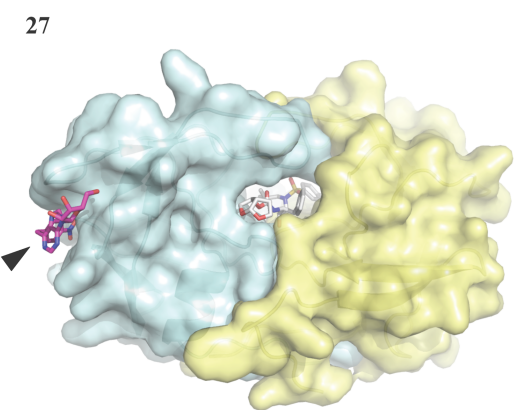

Fig S1. HIV PR subtype B wild-type in complex with compounds 18, 22, 27, 32 and 35.

Computer modeling of compounds $18,22,27,32$ and 35 binding in the hinge region of the crystal structure of the PR homodimer complexed with inhibitor Darunavir in the active-site. Computer modeling of compounds, indicated by a black arrow, bound in the hinge region of the crystal 
structure of the PR homodimer complexed with $\mathrm{PI}$ inhibitor in the active-site (1t3r, http://www.rcsb.org/pdb/).

\section{AD PQITLWQRPIVTIKIGGQLKEALLDTGADDTVLEDMNLPGRWKPKMIGGIGGFIKVRQYD 60 AD02 PQITLWQRPIVTIKVGGQLKEALLDTGADDTVLQEINLTGRWKPKMIGGIGGFAKVREYD 60 \\ AD QILIEICGHKAIGTVLVGPTPVNIIGRNLLTQLGCTLNF 99 \\ AD02 QVPIEICGHKAIGTVLVGPTPANIIGRNLLTQIGCTLNF 99}

Fig S2. Amino acid alignment of the HIV-1 AD and HIV-1 Ad02 PRs. Amino acid alignment based on Clustal Omega (http://www.ebi.ac.uk/Tools/msa/clustalo/) of the wild-type and (AD) and drugresistant (AD02) PRs. Resistant residues that differ between HIV-1 ${ }_{A D}$ and HIV-1 $1_{A D 02}$ are shown in red.

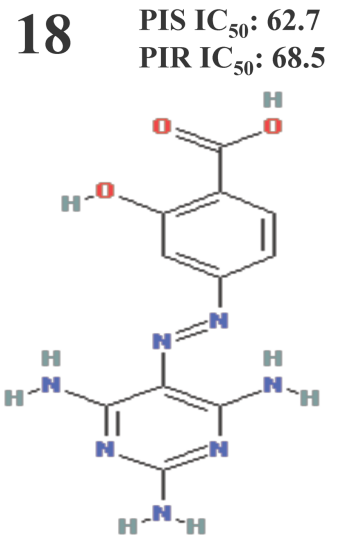

32 PIS IC $\mathrm{I0}_{50}: 3.8$ PIR IC $_{50}: 13.7$<smiles>Clc1ccccc1/C=N/Nc1nnc(N/N=C/c2ccccc2Cl)c2ccccc12</smiles>

$22 \quad$ PIS IC $_{50}: 53.5$

PIR IC $50: 71.9$<smiles>CCOC(=O)c1ncn2c1[nH]c(=S)c1ccccc12</smiles>

$35 \quad$ PIS IC $_{50}: 1.43$<smiles>N#Cc1c(NN)nc(Nc2cccc3ccccc23)c(C#N)c1C#N</smiles><smiles>O=[N+]([O-])c1ccc(Cc2ncnc3c2ncn3C2OC(CO)C(O)C2O)cc1</smiles> 
Fig S3. Chemical structure of the compounds. Chemical structure of the five lead compounds 18, 22, 27, 32 and 35. Next the identification number of each compound the $\mathrm{IC}_{50}$ against PIsensitive [PIS IC 50 ] or against multi PI-resistant $\mathrm{HIV}-1$ variant $\left[\mathrm{PIR} I \mathrm{C}_{50}\right]$ are given in $\mu \mathrm{M}$ range.

\begin{tabular}{|c|c|c|c|c|c|c|c|c|c|}
\hline \multirow{2}{*}{$\begin{array}{c}\text { Compounds } \\
\text { ID }\end{array}$} & \multicolumn{7}{c|}{ Cellular Toxicity in Presence of Compounds [ $\mu \mathrm{M}]$} \\
\cline { 2 - 11 } & \multicolumn{5}{c|}{ TZM-bl cells } & \multicolumn{4}{c|}{ PBMC } \\
\hline $\mathrm{NCl}$ & ID & $25^{1}$ & 50 & 100 & 200 & 10 & 25 & 50 & 200 \\
\hline 159456 & 1 & & & & & & & & \\
\hline 636983 & 8 & & & & & & & & \\
\hline 117285 & 18 & & & & & & & & \\
\hline 60044 & 19 & & & & & & & & \\
\hline 649152 & 22 & & & & & & & & \\
\hline 295274 & 27 & & & & & & & & \\
\hline 103650 & 32 & & & & & & & & \\
\hline 118210 & 34 & & & & & & & & \\
\hline 663619 & 35 & & & & & & & & \\
\hline 84120 & 36 & & & & & & & & \\
\hline 107192 & 37 & & & & & & & & \\
\hline 12994 & 39 & & & & & & & & \\
\hline
\end{tabular}

S1 Table. Toxicity of compounds in PBMC and TZM-bl cells. NCl: database number; ID: compound identification number; toxicity is expressed relative to viability of cells in DMSO: light grey, $\leq 10 \%$ or black, $>10 \%$. $\left({ }^{1}\right)$ Concentrations are expressed in $\mu \mathrm{M}$.

\begin{tabular}{|c|c|c|c|c|c|c|c|c|c|c|c|}
\hline \multirow{3}{*}{\multicolumn{2}{|c|}{$\begin{array}{c}\text { Concentrat } \\
\text { Compounds }\end{array}$}} & \multicolumn{10}{|c|}{ Fold change of compounds compared to $25 \mu \mathrm{M}$ RTV as reference } \\
\hline & & \multicolumn{5}{|c|}{$\mathrm{HIV}-1_{\mathrm{AD}}{ }^{1}$} & \multicolumn{5}{|c|}{ HIV-1 ADO2 $^{1}$} \\
\hline & & $18^{2}$ & 22 & 27 & 32 & 35 & 18 & 22 & 27 & 32 & 35 \\
\hline \multirow{6}{*}{$\begin{array}{l}\text { Compou } \\
\text { nds } \\
\text { alone }\end{array}$} & $\begin{array}{l}1 \\
\mu \\
M\end{array}$ & - & - & - & $\begin{array}{c}5.84 \\
(<.00 \\
01)\end{array}$ & - & - & - & - & $\begin{array}{c}6.86 \\
(<.00 \\
01)\end{array}$ & - \\
\hline & $\begin{array}{l}2 . \\
5 \\
\mu \\
M \\
\end{array}$ & - & - & - & $\begin{array}{c}7.14 \\
(<.00 \\
01)\end{array}$ & $\begin{array}{c}5.51 \\
(<.00 \\
01)\end{array}$ & - & - & - & $\begin{array}{c}6.85 \\
(<.00 \\
01)\end{array}$ & $\begin{array}{c}3.39 \\
(<.00 \\
01)\end{array}$ \\
\hline & $\begin{array}{l}1 \\
0 \\
\mu \\
M\end{array}$ & - & - & - & $\begin{array}{c}4.44 \\
(0.05 \\
97)\end{array}$ & $\begin{array}{l}6.18 \\
(<.00 \\
01)\end{array}$ & - & - & - & $\begin{array}{c}2.51 \\
(<.00 \\
01)\end{array}$ & $\begin{array}{l}6.18 \\
(<.00 \\
01)\end{array}$ \\
\hline & 25 & $\begin{array}{c}1.12 \\
(0.20 \\
14)\end{array}$ & $\begin{array}{l}1.48 \\
(0.01 \\
27)\end{array}$ & $\begin{array}{c}1.91 \\
(<.00 \\
01)\end{array}$ & - & $\begin{array}{c}5.90 \\
(<.00 \\
01)\end{array}$ & $\begin{array}{c}3.42 \\
(<.00 \\
01)\end{array}$ & $\begin{array}{c}3.77 \\
(<.00 \\
01)\end{array}$ & $\begin{array}{c}3.02 \\
(<.00 \\
01)\end{array}$ & - & $\begin{array}{c}5.90 \\
(<.00 \\
01)\end{array}$ \\
\hline & 50 & $\begin{array}{c}1.13 \\
(0.07 \\
42) \\
\end{array}$ & $\begin{array}{c}1.37 \\
(<.00 \\
01)\end{array}$ & $\begin{array}{c}1.90 \\
(<.00 \\
01)\end{array}$ & - & - & $\begin{array}{c}3.24 \\
(<.00 \\
01)\end{array}$ & $\begin{array}{c}3.03 \\
(<.00 \\
01)\end{array}$ & $\begin{array}{c}2.18 \\
(<.00 \\
01)\end{array}$ & - & 0.1 \\
\hline & 100 & $\begin{array}{r}0.87 \\
(0.01\end{array}$ & $\begin{array}{r}0.52 \\
(0.19\end{array}$ & $\begin{array}{c}1.16 \\
(0.78\end{array}$ & - & - & $\begin{array}{l}2.41 \\
(<.00\end{array}$ & $\begin{array}{l}2.18 \\
(<.00\end{array}$ & $\begin{array}{c}0.81 \\
(0.13\end{array}$ & - & - \\
\hline
\end{tabular}




\begin{tabular}{|c|c|c|c|c|c|c|c|c|c|c|c|}
\hline & & 33) & 75) & 56) & & & 01) & 01) & 63) & & \\
\hline \multirow{6}{*}{$\begin{array}{c}\text { Compou } \\
\text { nds } \\
\text { with } 25 \\
\mu \text { M RTV }\end{array}$} & $1 \mu$ & - & - & - & $\begin{array}{c}2.59 \\
0.027 \\
9 \\
\end{array}$ & - & - & - & - & $\begin{array}{c}1.60 \\
(<.00 \\
01)\end{array}$ & - \\
\hline & 2.5 & - & - & - & $\begin{array}{c}2.18 \\
(0.25 \\
95)\end{array}$ & $\begin{array}{c}2.40 \\
(0.39 \\
96)\end{array}$ & - & - & - & $\begin{array}{c}1.12 \\
(0.31 \\
57)\end{array}$ & $\begin{array}{c}2.40 \\
(0.01 \\
50)\end{array}$ \\
\hline & 10 & - & - & - & $\begin{array}{c}0.71 \\
(0.04 \\
73)\end{array}$ & $\begin{array}{c}2.84 \\
(0.83 \\
17)\end{array}$ & - & - & - & $\begin{array}{c}0.37 \\
(<.00 \\
01)\end{array}$ & $\begin{array}{c}2.84 \\
0.028 \\
9\end{array}$ \\
\hline & 25 & $\begin{array}{c}0.54 \\
(1.11 \\
62) \\
\end{array}$ & $\begin{array}{c}0.51 \\
(0.13 \\
69) \\
\end{array}$ & $\begin{array}{c}0.53 \\
(0.02 \\
86) \\
\end{array}$ & - & $\begin{array}{c}0.41 \\
(0.00 \\
11)\end{array}$ & $\begin{array}{c}0.75 \\
(0.02 \\
06) \\
\end{array}$ & $\begin{array}{c}1.18 \\
(0.15 \\
58)\end{array}$ & $\begin{array}{c}0.53 \\
(0.00 \\
44) \\
\end{array}$ & - & $\begin{array}{c}0.41 \\
(<.00 \\
01)\end{array}$ \\
\hline & 50 & $\begin{array}{c}0.32 \\
(1.12 \\
73)\end{array}$ & $\begin{array}{c}0.29 \\
(0.00 \\
21)\end{array}$ & $\begin{array}{c}0.32 \\
(0.00 \\
26)\end{array}$ & - & - & $\begin{array}{c}0.60 \\
0.001 \\
0\end{array}$ & $\begin{array}{c}0.57 \\
(<.00 \\
01)\end{array}$ & $\begin{array}{c}0.34 \\
(<.00 \\
01)\end{array}$ & - & - \\
\hline & 100 & $\begin{array}{c}0.40 \\
(0.87 \\
41)\end{array}$ & $\begin{array}{c}0.17 \\
(0.00 \\
11)\end{array}$ & $\begin{array}{c}0.13 \\
(0.00 \\
11)\end{array}$ & - & - & $\begin{array}{c}0.53 \\
(<.00 \\
01)\end{array}$ & $\begin{array}{c}0.63 \\
(<.00 \\
01)\end{array}$ & $\begin{array}{c}0.35 \\
(<.00 \\
01)\end{array}$ & - & - \\
\hline
\end{tabular}

S2 Table. Fold change of compounds $(18,22,27,32$ or 35$)$ alone or in combination with 25

MM RTV compared to $25 \mu \mathrm{M}$ RTV. P values are reported in parenthesis with Bonferroni correction with significance $p<0.0055$; fold change $>1$ indicates antiviral-activity less effective (viral replication higher) than $25 \mu \mathrm{M}$ RTV alone and significant ones are highlighted in green; fold change <1 indicates antiviral-activity more effective (viral replication lower) than $25 \mu \mathrm{M}$ RTV alone and significant ones are highlighted in yellow; (-) not performed. ( $\left.{ }^{1}\right)$ Anti-viral activity against HIV-1; ( ${ }^{2}$ ) Compounds identification number. 